\title{
Anaplastic large cell lymphoma ALK-negative clinically mimicking alcoholic hepatitis - a review
}

\author{
Fernando Peixoto Ferraz de Campos ${ }^{a}$, Aloísio Felipe-Silva ${ }^{b}$, Maria Claudia Nogueira Zerbinic
}

Campos FPF, Felipe-Silva A, Zerbini MCN. Anaplastic large cell lymphoma ALK-negative clinically mimicking alcoholic hepatitis - a review. Autopsy Case Rep [Internet]. 2013; 3(3): 11-19. http://dx.doi.org/10.4322/acr.2013.023

\section{ABSTRACT}

Anaplastic large cell lymphoma (ALCL), described less than 30 years ago by Karl Lennert and Herald Stein in Kiel, West Germany, is a T-cell or null nonHodgkin lymphoma, with distinctive morphology (hallmark cells, prominent sinus and/or perivascular growth pattern), characteristic immunophenotype $\left(\mathrm{CD} 30^{+}\right.$, cytotoxic granules protein,$\left.+ \mathrm{CD}^{-{ }^{-+}}\right)$and specific genetic features as translocations involving the receptor tyrosine kinase called anaplastic lymphoma kinase (ALK) on 2p23 and variable partners genes, which results in the expression of ALK fusion protein. The absence of ALK expression is also observed and is associated with poorer prognosis that seen with ALK expression. ALK-negative ALCL is more frequent in adults, with both nodal and extra nodal clinical presentation and includes several differential diagnoses with other $\mathrm{CD} 30^{+}$lymphomas. Liver involvement by ALCL is rare and is generally seen as mass formation; the diffuse pattern of infiltration is even more unusual. The authors present a case of a 72-year-old man who presented clinical symptoms of acute hepatic failure. The patient had a long history of alcohol abuse and the diagnosis of alcoholic hepatitis was highly considered, although the serum lactic dehydrogenase (LDH) value was highly elevated. The clinical course was fulminant leading to death on the fourth day of hospitalization. Autopsy demonstrated diffuse neoplastic hepatic infiltration as well as splenic, pulmonary, bone marrow, and minor abdominal lymph nodes involvement by the tumor. Based on morphological, immunophenotypical, and immunohistochemical features, a diagnosis of ALK- negative ALCL was concluded. When there is marked elevation of LDH the possibility of lymphoma, ALCL and other types, should be the principal diagnosis to be considered.

Keywords: Lymphoma, Large-Cell, Anaplastic; Liver Failure; Anaplastic Lymphoma Kinase; Autopsy.

\footnotetext{
a Department of Internal Medicine - Hospital Universitário - Universidade de São Paulo, São Paulo/SP - Brazil.

${ }^{\text {b } A n a t o m i c ~ P a t h o l o g y ~ S e r v i c e ~-~ H o s p i t a l ~ U n i v e r s i t a ́ r i o ~-~ U n i v e r s i d a d e ~ d e ~ S a ̃ o ~ P a u l o, ~ S a ̃ o ~ P a u l o / S P ~-~ B r a z i l . ~}$

c Department of Pathology - Faculdade de Medicina - Universidade de São Paulo, São Paulo/SP - Brazil.
}

Copyright $\odot 2013$ Autopsy and Case Reports - This is an Open Access article distributed of terms of the Creative Commons Attribution NonCommercial License (http://creativecommons.org/licenses/by/3.0/) which permits unrestricted non-commercial use, distribution, and reproduction in any médium provided article is properly cited. 


\section{CASE REPORT}

A 72-year-old man was admitted after a 60day history of poor appetite, progressive weakness, and marked weight loss. His family described mental confusion. Past medical history included hypertension and hypothyroidism under clinical treatment. He had been a heavy drinker since the age of 15 and had a smoking history as well.

On physical examination, he was emaciated, dehydrated, icteric, febrile (temperature $37.8{ }^{\circ} \mathrm{C}$ ), with tachycardia and tachypnea. Blood pressure was normal. The patient was alert and conscious with spontaneous eye opening, and responded to simple commands. Extrinsic and intrinsic ocular motor function was normal. No extraocular motor deficits were seen, and there was no neck stiffness. Hepatic flapping was not present. No lymph adenomegaly was detected, and the heart and lungs examination was unremarkable. The abdomen was diffusely tender, predominantly in the right hypochondrium where the liver was slightly enlarged. The spleen was not palpable, and there was no sign of peritoneal irritation. The initial laboratory workup is shown in Table 1.

Urinalysis showed mild proteinuria, elevated cell count and granular cylindruria, which were interpreted as compatible with chronic hepatopathic glomerulitis. Serologic tests for HIV, human T-cell lymphoma/leukemiavirus(HTLV)-I, HTLV-II, hepatitis
$\mathrm{C}$ and $\mathrm{B}$, as well as Epstein-Barr virus (EBV), were negative. Plasma protein electrophoresis did not show the presence of an anomalous peak. Serum alpha-fetoprotein value was less than $1.3 \mathrm{ng} / \mathrm{mL}$ (reference value [RV] less than $8 \mathrm{ng} / \mathrm{mL}$ ). Blood and urine cultures were negative.

Considering the history of intense and long-term alcohol abuse, and the complaints of appetite loss, weakness with associated mental confusion, icterus and laboratory data showing marked leukocyte shift to the left, elevation of the total bilirubin, and hepatocellular enzyme values (aspartate aminotransferase [AST] greater than twice the alanine aminotransferase [ALT]), the diagnosis of alcoholic hepatitis with hepatic failure was strongly considered. The presence of infection was uncertain. The determination of canalicular enzymes within the normal limits as well as the absence of other stigmata of chronic hepatic disease remained odd, as well as the elevated determination of lactic dehydrogenase (LDH) not typical for alcoholic hepatic disease. The patient was admitted and treated with antibiotics, saline intravenous infusion, and thiamine supplementation. On the following days, as the clinical picture deteriorated and the Maddrey score ${ }^{d}$ reached 88 , corticosteroid was added to the therapeutic regimen. Hepatic and renal function continued worsening, the platelet count dropped to $8000 / \mathrm{mm}^{3}$, he became comatose, and died on the fourth day of his hospital stay.

Table 1 - Initial laboratory workup

\begin{tabular}{|c|c|c|c|c|c|}
\hline Exam & Results & RV & Exam & Results & RV \\
\hline Hemoglobin & 11.7 & $12.3-15.3 \mathrm{~g} / \mathrm{dL}$ & Urea & 181 & $5-25 \mathrm{mg} / \mathrm{dL}$ \\
\hline Hematocrit & 37.1 & $36.0-45.0 \%$ & Creatinine & 2.0 & $0.4-1.3 \mathrm{mg} / \mathrm{dL}$ \\
\hline Leukocytes & 5.8 & $4.4-11.3 \times 10^{3} / \mathrm{mm}^{3}$ & Potassium & 3.8 & 3.5-5.0 mEq/L \\
\hline Prom/myel/metam & $1 / 1 / 1$ & 0 & Sodium & 140 & $136-146 \mathrm{mEq} / \mathrm{L}$ \\
\hline Bands & 17 & $1-5 \%$ & ALT & 67 & 9-36 U/L \\
\hline Segmented & 71 & $45-70 \%$ & AST & 237 & $10-31 \mathrm{U} / \mathrm{L}$ \\
\hline Eosinophils & 0 & $1-4 \%$ & AF & 84 & $10-100 \mathrm{U} / \mathrm{L}$ \\
\hline Basophils & 0 & $0-2.5 \%$ & yGT & 24 & $2-30 \mathrm{U} / \mathrm{L}$ \\
\hline Lymphocytes & 0 & $18-40 \%$ & Total bilirubin & 6.3 & $0.3-1.2 \mathrm{mg} / \mathrm{dL}$ \\
\hline Monocytes & 0 & $2-9 \%$ & Total protein & 4.79 & $6-8 \mathrm{~g} / \mathrm{dL}$ \\
\hline Platelets & 30 & $150-400 \times 10^{3} / \mathrm{mm}^{3}$ & Albumin & 2.3 & $3-5 \mathrm{~g} / \mathrm{dL}$ \\
\hline CRP & 486 & $<5 \mathrm{mg} / \mathrm{L}$ & LDH & 760 & $120-246$ \\
\hline INR & 1.46 & 1.0 & Lactate & 75.9 & $4.5-19.8 \mathrm{mg} / \mathrm{L}$ \\
\hline
\end{tabular}

$\mathrm{AF}=$ alkaline phosphatase; $\mathrm{ALT}=$ alanine aminotransferase; $\mathrm{AST}=$ aspartate aminotransferase; CRP = Creactive protein; $\mathrm{yGT}=$ gamma glutamyl transferase; INR = international normalized ratio; LDH = lactic dehydrogenase; metam = metamyelocyte; myel = myelocyte; prom = promyelocyte; $\mathrm{RV}=$ reference value.

${ }^{\mathrm{d}}$ Maddrey WC, Boitnott JK, Bedline MS, et al. Corticosteroid therapy for alcoholic hepatitis. Gastroenterology. 1978;75:193-9. 


\section{AUTOPSY FINDINGS}

The external examination showed a normally developed icteric man, with moderate edema of the lower limbs and genitalia. Few but large ecchymosis were over the abdomen and flanks.

Viscera were bile stained. Multiple hemorrhagic foci were in the abdominal viscera and left cerebellar lobe.

The thoracic cavity contained $150 \mathrm{cc}$ of serous pleural effusion. Right lung weighed $905 \mathrm{~g}$ (reference mean value [RMV]: $450 \mathrm{~g}$ ) and the left lung $845 \mathrm{~g}$ (RMV: $375 \mathrm{~g}$ ). Lungs were wine-colored and were markedly edematous; multiple scattered friable purulent foci were present, mainly at the right base. Few small, round, firm lymph nodes were in the pulmonary hila. Cardiovascular examination showed marked aortic, coronary and renal artery atherosclerosis

The abdominal cavity contained $350 \mathrm{cc}$ of clear yellow-citrine ascites. Multiple mildly enlarged lymph nodes were found, particularly periaortic and at the splenic hilum, measuring up to $2.5 \mathrm{~cm}$. They were homogeneous white with effaced nodal architecture on the cut surface (Figure 1A). The spleen was enlarged, weighing $445 \mathrm{~g}$ (RMV: $112 \mathrm{~g}$ ). The splenic parenchyma was markedly congested and friable. Two triangular subcapsular areas $(1-3 \mathrm{~cm})$ of infarction were present (Figure 1B). The liver was enlarged, yellowish, softened, and weighed $2516 \mathrm{~g}$ (RMV: $1600 \mathrm{~g}$ ). The surface was nodular. The cut surface showed a mottled pattern with congested wine-colored central areas surrounded by pale yellow halos (Figure $1 \mathrm{C}$ ). Two thin-walled cysts measuring up to $4.5 \mathrm{~cm}$ corresponding to simple biliary cysts were present. Exaggerated mottling was noted on serial slicing (Figure 1D).
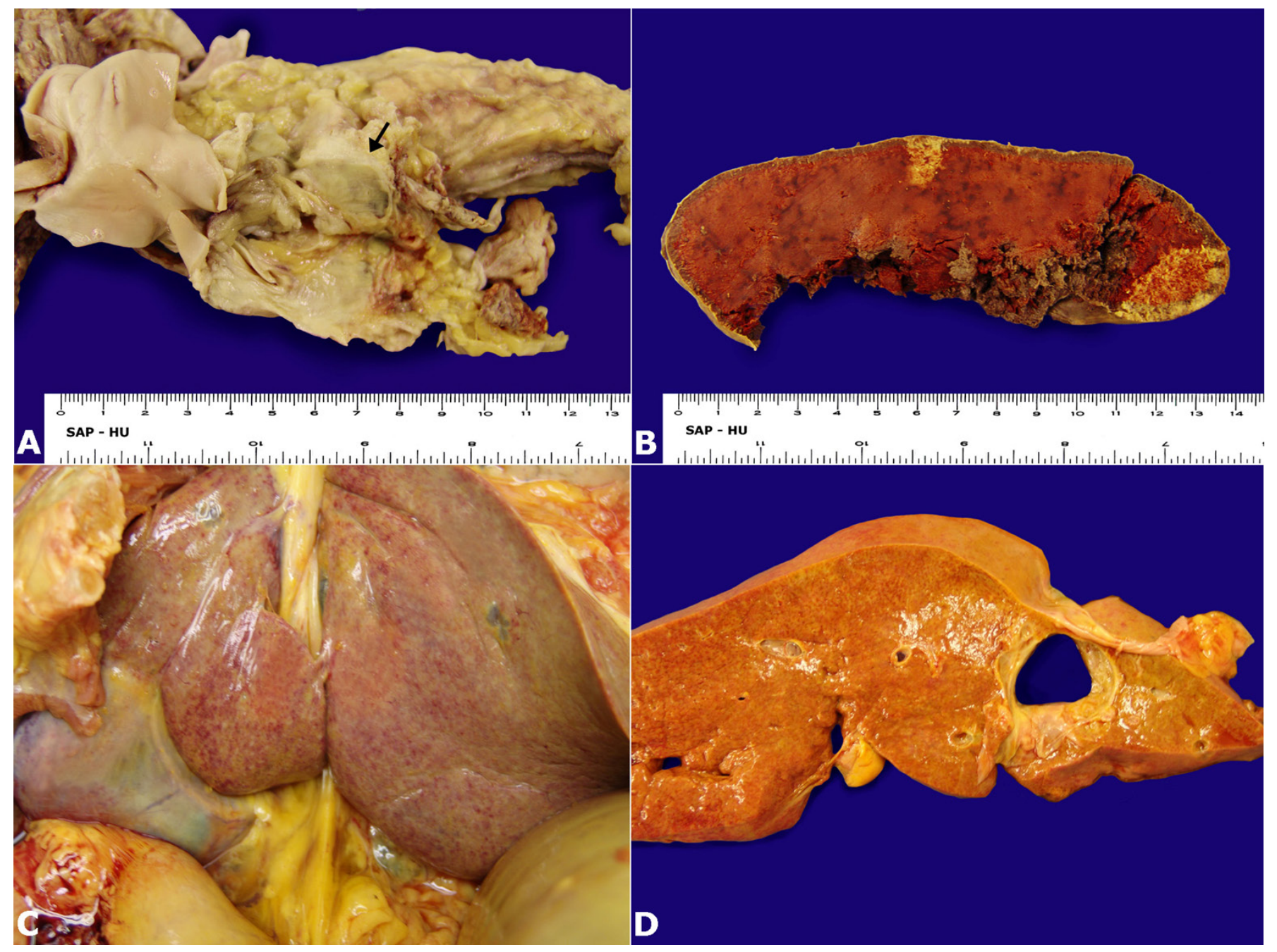

Figure 1 - Gross appearance of: A - periaortic lymph node (arrow); B - splenic cut surface showing two areas of infarction; C - hepatic irregular capsular surface with mottled pattern; and $\mathbf{D}$ - hepatic cut surface showing a cystic lesion and the diffuse mottled pattern of the parenchyma characterized by congested winecolored central areas surrounded by pale halos. Besides biliary cysts, no focal lesions were detected. 
Microscopically extensive infiltration by a diffuse population of atypical large pleomorphic cells was observed in the liver, spleen, and lymph nodes. These cells typically exhibited horseshoe or kidney-shaped nuclei with prominent nucleoli and a moderate amount of pink cytoplasm ("hallmark cells") (Figure 2A).

Neoplastic cells were positive for CD30 (diffuse) (Figure 2B), CD45 (Figure 2C) and CD2 (focal) (Figure 2D). Immunostaining for ALK, perforin, TIA1, epithelial membrane antigen (EMA), anaplastic lymphoma kinase (ALK), CD3, CD20, CD15, EBV (LMP1), PAX5, and CD138 were negative.

Hepatic involvement was characterized by extensive diffuse neoplastic infiltration of the portal space and the lobular parenchyma. Hepatocytes exhibited slight macro vesicular steatosis
(Figures $3 \mathrm{~A}$ and $3 \mathrm{~B}$ ) and hemorrhagic necrosis in zone 3. Typical features of alcoholic hepatitis (massive steatosis, balloon cells, Mallory hyaline, early zone 3 pericellular fibrosis) were not present. The lungs had perivascular foci of neoplastic cells and a marked intraalveolar edema (Figures $3 \mathrm{C}$ and 3D).

In addition to infarcts, the spleen showed extensive angiocentric neoplastic infiltration involving white and red pulp (Figures 4A and 4B). The lymph node architecture was effaced by the diffuse infiltration of neoplastic cells with the same pattern of involvement (Figure 4C). Extensive neoplastic cell necrosis was also present (Figure 4D).

Shock-related lesions were present in the kidneys, which showed acute tubular necrosis, and in the small bowel, which showed as ischemic enteritis. Based on the neoplastic morphology

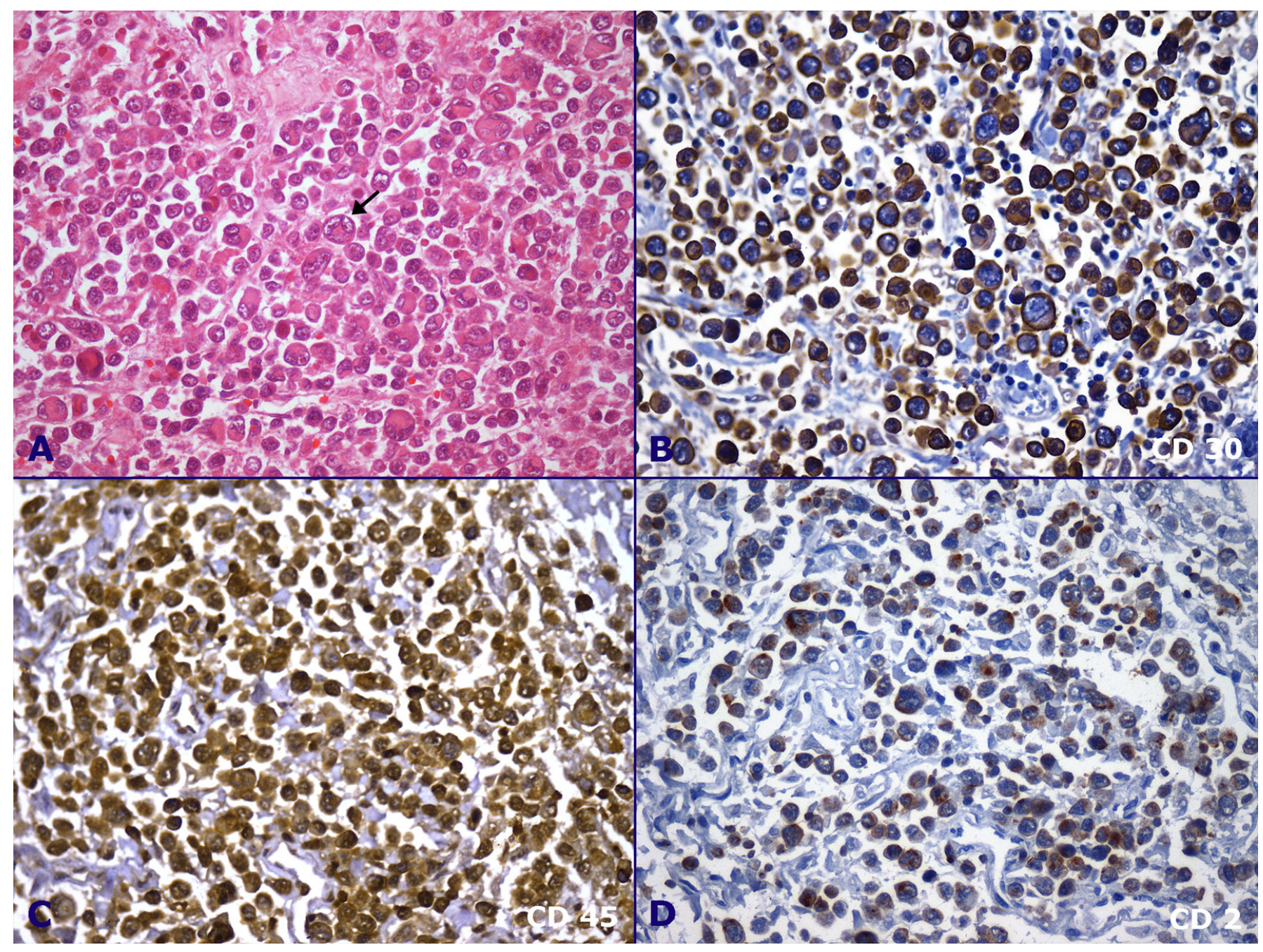

Figure 2 - Photomicrography of a lymph node. A - Extensive infiltration by atypical large pleomorphic cells exhibiting eccentric, irregular, bi or multinucleated, wreath-shaped nucleus (arrow), with distinct nucleoli (HE 100X); B - Immunostaining for CD 30 (40X); C - Immunostaining for CD 45 (40X); D - Immunostaining for CD 2 (20X). 


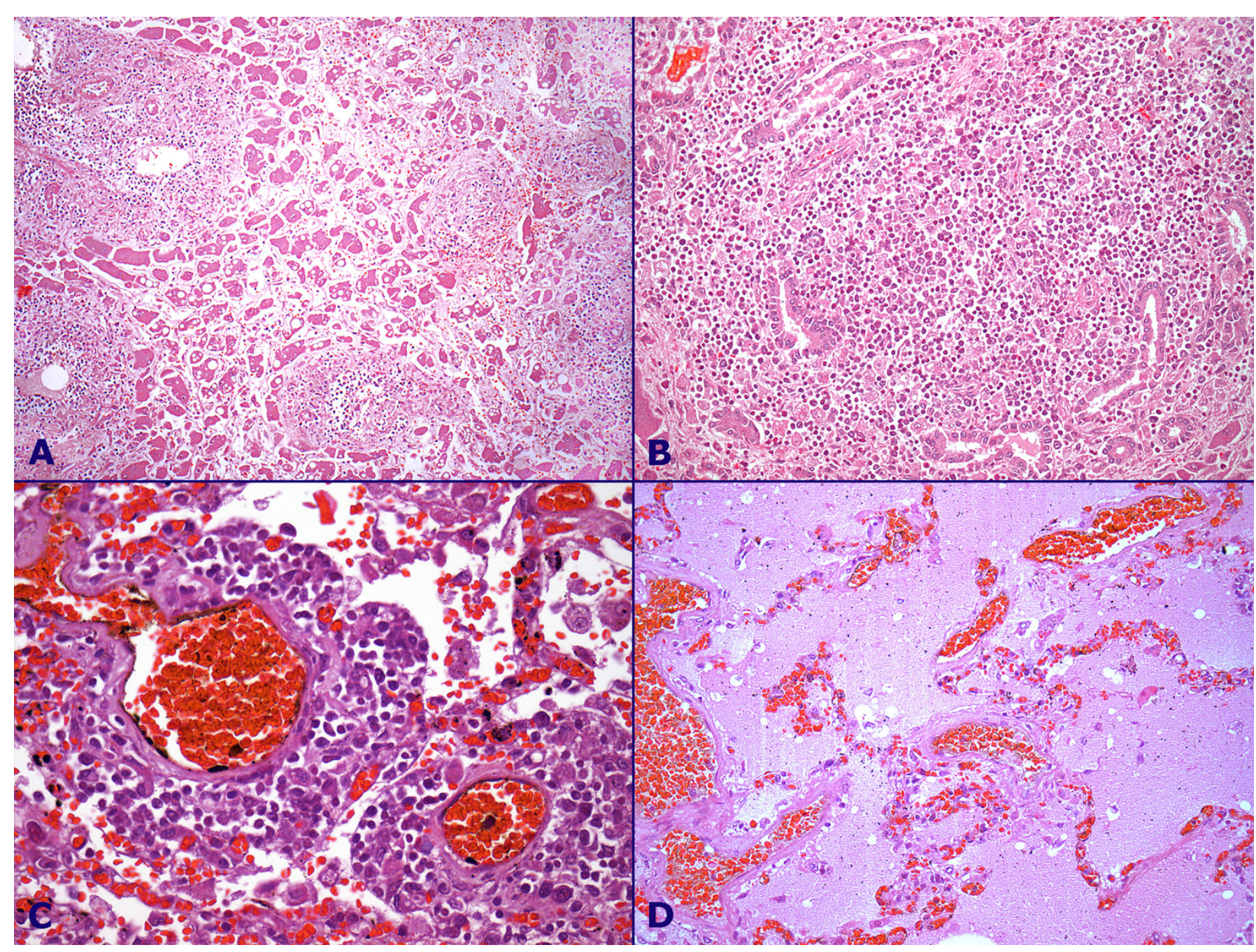

Figure 3 - A and B - Photomicrography of the liver showing neoplastic infiltration of the lobular parenchyma and portal space (detailed in B); note the focal macrovesicular steatosis; C and D - Photomicrography of the lung showing perivascular tumoral infiltration pattern $(C)$ and marked pulmonary edema (D).

and immunophenotypic features, the diagnosis of anaplastic large cell lymphoma (ALCL), ALKnegative was established.

\section{DISCUSSION}

Anaplastic large cell lymphoma (ALCL) was often misdiagnosed in the past as metastatic carcinoma, melanoma, or malignant histiocytosis. The concept of ALCL evolved during the last two decades to a distinct molecular pathologic entity. ${ }^{1}$ In 1985, Harald Stein and Karl Lennert with colleagues ${ }^{2}$ first described the anaplastic large cell lymphoma, delineating a type of tumor with an unusual sinus growth pattern, which strongly expressed CD30 (formerly called Ki-1 antigen) on the cell membrane and other lymphoid markers, but lacked the expression of molecules associated with histiocytic or other cell lineages. ${ }^{3}$ At first, many questioned this diagnosis as a distinct entity, since the expression of
CD30 could also be seen in reactive processes and other tumors. Some years later, the chromosome translocation $t(2 ; 5)(p 23, q 35)$ was demonstrated in ALCL cases. ${ }^{4}$ Subsequent cloning of the chromosomal breakpoints showed that the affected genes were ALK, located at chromosome 2p23, and NPM (encoding nucleophosmin) located at $5 q 35.5,6$ The $t(2 ; 5)$ is the most common karyotypic aberration involving ALK, present in approximately $75 \%$ of the ALCLs with ALK rearrangements, and is the only well-known gene partner that imparts a nuclear pattern of $\mathrm{ALK}^{+}$immunostain. ${ }^{7}$ In approximately $25 \%$ of the remaining cases, a number of variant rearrangements involving $2 \mathrm{p} 23$ are seen, including $\mathrm{t}(1 ; 2)(\mathrm{q} 21 ; \mathrm{p} 23), \quad$ inversion 2(p23;q35), $\mathrm{t}(2 ; 3)$ $(p 23 ; q 21), \quad t(2 ; 17)(p 23 ; q 23)$, and $t(X ; 2)(q 11-$ 12;p23). ${ }^{5,7}$ These chromosomal abnormalities result in the overexpression of the fusion protein ALK. After widespread immunohistochemical analysis with anti-ALK monoclonal antibodies, $\mathrm{ALK}^{+} \mathrm{ALCL}$ was defined as a specific entity, and ALK immunostaining is considered a surrogate marker for the genetic 




Figure 4 - A and $\mathbf{B}$ - Photomicrography of the spleen, showing in (A) perivascular tumoral infiltration pattern; and $(B)$ white and red pulp tumoral infiltration; C and D - Photomicrography of the lymph node, showing in (C) diffuse infiltration of neoplastic cells; and (D) neoplastic cell necrosis.

aberration involving the ALK gene. Tumors with the same characteristics, but without expression the ALK protein, are called ALCL ALK-negative, and are associated with a worse prognosis than $\mathrm{ALK}^{+}$ tumors.

The immunophenotype of these neoplastic cells was shown to be T-cell or null cell depending on the number of T-cell antigens tested. In the case reported here, the lineage markers were based on CD3 and CD2 because other cell markers such as CD5 and CD43 did not present reliable staining. This technical failure may be related to inherent autopsy limitation, even in the era of powerful detection/ amplification systems. It is believed that most, if not all, of the null cell cases belong to the T-cell type, as demonstrated by the presence of the T-cell receptor (TCR) gene rearrangement. ${ }^{3}$ The Revised European-American Lymphoma (REAL) and the new $\mathrm{WHO}$ classification include B-cell ALCL with all other diffuse large B-cell non-Hodgkin lymphomas (NHLs), whereas ALCL of T-cell or null phenotype is considered a distinct disease entity. ${ }^{8,9}$ In 2008 , the WHO classification separated the ALCL ALK ${ }^{+}$ from those ALK-negative which are morphologically similar to the $\mathrm{ALK}^{+}$but do not express the ALK protein. ${ }^{10,11}$ However, In this classification the WHO considered the ALK-negative ALCL as a provisional entity. Most cases express T-cell-associated and cytotoxic markers and must be distinguished from primary cutaneous ALCL, other subtypes of $\mathrm{CD} 30^{+}$ T- or B-cell lymphoma with anaplastic features, and classical Hodgkin lymphoma. ${ }^{12}$ ALCL can be distinguished from Hodgkin lymphoma by the presence of ALK fusion protein in ALCL-ALK ${ }^{+}$, and by PAX5 staining which shows expression in Hodgkin lymphoma but is negative in ALK-negative ALCL. ${ }^{12}$

More recently, Feldman et al. ${ }^{13}$ demonstrated the translocation $\mathrm{t}(6 ; 7)(\mathrm{p} 25.3 ; \mathrm{q} 32.3)$ in ALKnegative $A L C L,{ }^{12}$ but an immunohistochemical marker that can be used as a surrogate indicator of this translocation is still lacking. 
Except for the small cell variant, this tumor is characterized by a proliferation of cohesive clusters of pleomorphic large lymphoid cells, with a high mitotic index, strongly positive for CD30 and CD4. Expression of EMA and cytotoxic granule proteins are usually present but may lack in ALK-negative $\mathrm{ALCL}^{1}$ as was observed in our case. The large cells exhibit a marked characteristic morphology, represented by an eccentric, irregular, horseshoe, kidney or wreath-shaped nuclei, with distinct nucleoli and abundant cytoplasm, infiltrating the lymph node in a prominent sinus pattern simulating metastatic solid tumors. ${ }^{1,5,14}$ Multinucleated cells with ReedSternberg-like appearance may also occur. ${ }^{3}$ Extra nodal infiltration may wipe out the organ architecture by solid, cohesive sheets of neoplastic cells. ${ }^{12}$ Another morphologic characteristic is the disposition of the large cells surrounding small vessels ("angiocentric"), which is evident with immunostaining for CD30, which highlights the anaplastic cells. ${ }^{3}$

Because of the wide histologic spectrum of the tumor cell population and the admixture of reactive cells, ALCL is classified in subtypes, namely: common or classic (pleomorphic type are $30-50 \%$ $\mathrm{ALK}^{+}$, monomorphic type $\left.>80 \% \mathrm{ALK}^{+}\right)$; giant-cell rich $\left(30-40 \% \mathrm{ALK}^{+}\right)$, small-cell $\left(75 \%\right.$ are $\left.\mathrm{ALK}^{+}\right)$, lymphohistiocytic $\left(60 \%\right.$ are $\left.\mathrm{ALK}^{+}\right)$, Hodgkin-like $\left(<20 \% \mathrm{ALK}^{+}\right)$and other rare variants. ${ }^{3,5}$ Among the ALK-negative neoplasias within this classification, only the classical morphology is accepted as ALCL, whereas the small-cell and lymphohistiocytic subtypes should rather be classified as peripheral T-cell lymphoma, not otherwise specified (PTCL, NOS). The diagnosis of ALK- negative ALCL is reserved for cases, which present all the features of ALCL ALK+, except for the expression of ALK. In the case reported here, the form of presentation as a diffuse disease did not allow the evaluation of a sinusoidal pattern, but "hallmark cells" and CD30 diffusely positive were present.

ALCL can exist as either a widespread systemic syndrome, or as a localized disease. ALCL systemic type comprises 2-3\% of non-Hodgkin lymphomas (NHLs) in adults, and $15 \%$ of the $\mathrm{NHL}$ in pediatrics. ${ }^{1,12,15}$ Among all systemic ALCL, 15$50 \%$ are ALK-negative. These tumors affect adults with the median age of 55-60 years with no gender predominance; two-thirds of them present stage III or IV at diagnosis, with B symptoms and high international prognostic index (IPI) score. Lymph node involvement is present in $49 \%$ of the patients at the diagnosis. Extranodal involvement occurs in the skin, bone, and soft tissues. ${ }^{1}$ Gastrointestinal tract, hard palate, nasal cartilage, ovary, bronchus, psoas muscle, ocular adnexa, pleura, testis, and breast are only rarely involved. ${ }^{1}$ Bone marrow involvement is found in $10-30 \%$ of cases, but is present in as many as $61 \%$ of cases when molecular studies are added to the investigation. ${ }^{1,16,17}$ Central nervous system involvement and leukaemic phase are rare. Peripheral blood involvement may be seen in pediatric $\mathrm{ALK}^{+} \mathrm{ALCL}$ cases or in adults $\mathrm{ALCL}$ ALK-negative and may be represented by elevated white blood cell count owing to neutrophilia induced by granulocyte-colony stimulating factor produced by the tumor. Rare patients with ALCL have a hemophagocytic syndrome. ${ }^{1}$ Compared with the ALCL ALK+, the prognosis of ALCLs ALK-negative is much worse.

ALK expression is not unique to ALCL. Since the discovery of ALK in the mid-nineties, the number of neoplasms expressing this protein has expanded. One of the benefits of recognizing ALK in these tumors relates to targeted therapy, a new approach in the treatment of these neoplasias with promising outcomes. Selective kinase inhibitors are one of the most important classes of these medications. As ALK has limited expression in human tissues, it turns to an appealing oncogene to target. ${ }^{18}$

Liver involvement by $\mathrm{NHL}$ can be predominantly secondary, commonly found in advanced diseases; or primary, when the staging investigations failed to show extrahepatic disease (stage IE) or if the disease is predominant in the liver at presentation. In the latter situation, infiltration can be identified at other sites, including the spleen, regional lymph nodes and bone marrow. Some investigators prefer to describe the latter situation as "predominant liver involvement."19,20 Grossly, hepatic involvement can be as a solitary tumor, multiple nodular masses, or a diffusely infiltrative process, ${ }^{19,21,22}$ which, although being the less frequent, was the pattern in our patient. Many histologic types of lymphoma affect hepatic parenchyma. Among them, ALCL has been reported to be involved in $7-17 \%$ of all the hepatic lymphomas. ${ }^{3,19,23}$ Clinically, hepatic involvement can vary since asymptomatic disease, recognized during evaluation for incidental hepatic testing abnormality, to fulminant liver failure.

Saikia et al., ${ }^{22}$ reported two cases of ALCL that presented as acute hepatic failure and retrieved six other cases with the same histology. In general, the first symptoms are nonspecific, such 
as abdominal discomfort, right upper quadrant pain, fever, weight loss, and anorexia, very similar to the clinical presentation of this case report. Hepatomegaly is detected in up to $82 \%$ of cases and jaundice is usually a late manifestation of disease progression, generally associated with periportal adenopathy or underlying cirrhosis. ${ }^{19,24}$ There is no identifiable specific laboratory pattern for hepatic lymphoma, reflecting the wide histologic and anatomic heterogeneity of the disease.

However, it is quite common to have at least one altered liver function test and particularly an elevation of LDH determination. $\mathrm{LDH}$ is recognized as a non-specific biochemical marker of lymphomas. In our case, the elevation of LDH was not typical for alcoholic hepatitis, and should have led to the consideration of lymphoma. Thrombocytopenia documented in many reports of hepatic involvement by lymphoma. Rare associations with immune thrombocytopenia have been described. ${ }^{25}$ Lettieri and Berg, $^{26}$ described one case with thrombocytopenia in a series of five, and report the occurrence of thrombocytopenia in $86 \%$ of $\mathrm{NHL}$ liver infiltration in the same article. Besides the immune mechanisms, disseminated intravascular coagulopathy and hypersplenism should also be considered. In our patient, splenomegaly and bone marrow involvement could contributed to cytopenia, but isolated thrombocytopenia would be unusual.

Radiographic imaging has not been successful in distinguishing hepatic lymphoma from other liver diseases. Diffusely infiltrative disease, as was the presentation of this case report, can present as hepatomegaly with little alteration in parenchymal density or architectural distortion. ${ }^{19}$ CT images in our patient, except for the findings of areas compatible with splenic infarction and detection of few small periaortic lymph nodes, did not suggest other diagnoses apart from chronic liver disease.

Although rare, advanced liver failure can be caused by lymphomatous infiltration of the liver. ${ }^{26}$ This condition is observed when the hepatic parenchyma is replaced by diffuse intrasinusoidal propagation of tumor cells, as is often seen in gamma-delta hepatosplenic lymphoma. ${ }^{27}$ Because of the epidemiological data concerning alcoholic abuse, clinical symptoms resembling alcoholic hepatitis, the absence of palpable adenomegaly, a lack of specific diagnostic imaging, and the rarity of the liver involvement by ALCL, the diagnosis of ALCL was not recognized during life and was only established by the autopsy, emphasizing, once again, the important diagnostic and teaching value of this medical tool.

Therefore, we call attention to this unusual cause of hepatic failure, in which generally occurs in patients without a previous diagnosis of hepatic disease. If laboratory study results are not typical for liver disease and, particularly, when LDH determination is unexpectedly and significantly elevated, the possibility of lymphoma should be suspected. Percutaneous liver biopsy would certainly establish the correct diagnosis. In our patient the clinical status deteriorated quickly, making biopsy itself of high risk.

\section{REFERENCES}

1. Kinney MC, Higgins RA, Medina EA. Anaplastic large cell lymphoma. Twenty-five years of discovery. Arch Pathol Lab Med. 2011;135:19-43. http://dx.doi.org/10.1043/20100507-RAR. 1

2. Stein H, Mason DY, Gerdes J, et al. The expression of the Hodgkin disease associated antigen $\mathrm{Ki}-1$ in reactive and neoplastic lymphoid tissue: evidence that Reed-Sternberg cells and histiocytic malignancies are derived from activated lymphoid cells. Blood. 1985;66:848.

3. Stein H, Foss HD, Durkop H, et al. CD30+ anaplastic large cell lymphoma: a review of its histopathologic, genetic, and clinical features. Blood. 2000;96:3681-95.

4. Rimokh R, Magaud JP, Berger F, et al. A translocation involving a specific breakpoint (q35) on chromosome $5 \mathrm{i}$ is characteristic of anaplastic large cell lymphoma ("Ki-1 lymphoma"). Br J Haematol.1989;73:806.

5. Kutok JL, Aster JC. Molecular Biology of Anaplastic Lymphoma Kinase- Positive Anaplastic Large-Cell Lymphoma. J Clin Oncol. 2002;20:3691-702.

6. Morris SW, Kirstein MN, Valentine MB, et al. Fusion of a kinase gene, ALK, to a nucleolar protein gene, NPM, in non-Hodgkin's lymphoma. Science. 1994;263:1281-4. http:// dx.doi.org/10.1126/science. 8122112

7. Duyster J, Bai RY, Morris SW. Translocations involving anaplastic lymphoma kinase (ALK). Oncogene. 2001;20:562337.

8. Gascoyne RD, Aoun P, Wu D, et al. Prognostic significance of anaplastic lymphoma kinase (ALK) protein expression in adults with anaplastic large cell lymphoma. Blood. 1999;93:3913-21.

9. Stansfeld AG, Diebold J, Noel H, et al. Updated Kiel classification for lymphomas [published erratum appears 
in Lancet 1:372, 1988]. Lancet.1988;1:292. http://dx.doi. org/10.1093/annonc/mdh392

10. Mason DY, Harris NL, Delsol G, et al. Anaplastic large cell lymphoma, ALK-negative. In: Swerdlow SCE, Campo E, Harris NL et al., editors. WHO classification of tumors of haematopoietic and lymphoid tissues. Lyon: IARC; 2008. p. 317-9.

11. Delsol G, Falini B, Müller-Hermelink HK, et al. Anaplastic large cell lymphoma (ALCL), ALK-positive. In: Swerdlow SCE, Campos E, Harris NL, et al, editors. WHO classification of tumors of haematopoietic and lymphoid tissues. Lyon: IARC; 2008. p. 312-6.

12. Ferreri AJM, Govi S, Pileri SA, Savage KJ. Anaplastic large cell lymphoma, ALK-negative. Crit Rev Oncol Hematol. 2013;85:206-15. http://dx.doi.org/10.1016/j. critrevonc.2012.06.004

13. Feldman AL, Dogan A, Smith DI, et al. Discovery of recurrent $\mathrm{t}(6 ; 7)(\mathrm{p} 25.3 ; \mathrm{q} 32.3)$ translocations in ALK-negative anaplastic large cell lymphomas by massively parallel genomic sequencing. Blood. 2011;117:915-9. http://dx.doi. org/10.1182/blood-2010-08-303305

14. Benharroch D, Meguerian-Bedoyan Z, Lamant L. ALKpositive lymphoma: a single disease with a broad spectrum of morphology. Blood. 1998;91:2076-84.

15. Coiffier B. Treatment of aggressive non-Hodgkin's lymphoma. Semin Oncol. 1999;26:12-20.

16. Fraga $M$, Brousset $P$, Schaifer $D$, et al. Bone marrow involvement in anaplastic large cell lymphoma. Am J Pathol. 1995;103:82.

17. Savage KJ, Harris NL, Vose JM, et al. ALK- anaplastic largecell lymphoma is clinically and immunophenotypically different from both $A L K+A L C L$ and peripheral T-cell lymphoma, not otherwise specified: report fom the International Peripheral
T-Cell Lymphoma Project. Blood. 2008;111:5496-504. http:// dx.doi.org/10.1182/blood-2008-01-134270

18. Minoo P, Wang HY. ALK-immunoreactive neoplasms. Int J Clin Exp Pathol. 2012;5:397-410.

19. Salmon JS, Thompson MA, Arildsen RC, et al. Non-Hodgkin's lymphoma involving the liver: clinical and therapeutic consideration. Clin Lymphoma Myeloma 2005;6:273-80. http://dx.doi.org/10.3816/CLM.2006.n.001

20. Aozasa K, Mishima K, Ohsawa M. Primary malignant lymphoma of the liver. Leuk Lymphoma. 1993;76:1336-43.

21. Lei $\mathrm{KI}$, Chow JH, Johnson PJ. Aggressive primary hepatic lymphoma in Chinese patients. Cancer. 1995;76:1336-43.

22. Saikia UN, Sharma N, Duseja A, Bhalla A, Joshi K. Anaplastic large cell lymphoma presenting as acute liver failure: $A$ report of two cases with review of literature. Ann Hepatol. 2010;9:457-61.

23. Tilly H, Gaulard P, Lepage E, et al. Primary anaplastic large cell lymphoma in adults: clinical presentation, immunophenotypes, and outcome. Blood. 1997;90:3727-34.

24. Lei KI. Primary non-Hodgkin's lymphoma of the liver. Leuk Lymphoma. 1998;29:293-9.

25. Aghai E, Quitt M, Lurie M, et al. Primary hepatic lymphoma presenting as symptomatic immune thrombocytopenia purpura. Cancer. 1987;60:2308-11.

26. Lettieri CJ, Berg BW. Clinical features of non-Hodgkin lymphoma presenting with acute liver failure: a report of five cases and review of published experience. Am J Gastroenterol. 2003;98:1641-6.

27. Myszor M, Record CO. Primary and secondary malignant disease of the liver and fulminat hepatic failure. J Clin Gastroenterol. 1990;12:441-6.

\section{Conflict of interest: None}

Submitted on: $17^{\text {th }}$ July 2013

Accepted on: $22^{\text {th }}$ August 2013

Correspondence: Departamento de Patologia

Faculdade de Medicina da Universidade de São Paulo

Av. Dr. Arnaldo, 455 - Cerqueira César - São Paulo/SP - Brazil

CEP: 01246-903 - Phone: +55 (11) 3061-7234

E-mail: czerbini@usp.br 
